\title{
USO DE DINÂMICA DE SISTEMAS COMO SUPORTE À DECISÃO EM PROPRIEDADES PRODUTORAS DE LEITE: UM ESTUDO DE CASO ${ }^{1}$
}

\author{
William R.B. Ávila ${ }^{2}$ \\ Viviani Silva Lirio ${ }^{3}$ \\ Maurinho Luiz dos Santos ${ }^{4}$ \\ Wilson da Cruz Vieira ${ }^{5}$
}

\begin{abstract}
Resumo - Acredita-se que grande parte do sucesso na pecuária leiteira esteja diretamente relacionada com o nível gerencial adotado nessa atividade; assim, uma vez evidenciada a necessidade de aprimoramento dos processos decisórios nas empresas rurais desse setor, objetivou-se, neste trabalho, desenvolver uma ferramenta de suporte à decisão, baseada em princípios de dinâmica de sistemas. A simulação dos modelos matemáticos tornou-se possível por meio da utilização de dados obtidos a partir de uma representativa unidade de produção de leite, localizada em Minas Gerais, Brasil. Os resultados encontrados nas simulações mostraram-se coerentes com análises sistêmicas previamente estabelecidas. Pôde-se observar a relevante contribuição da dinâmica de sistemas para o aumento da compressão do funcionamento desse sistema de produção, bem como a viabilidade da utilização desse instrumento computacional no planejamento estratégico da bovinocultura de leite.
\end{abstract}

Palavras-chave: Dinâmica de sistemas, pecuária de leite, planejamento estratégico.

\footnotetext{
${ }^{1}$ Parte da dissertação de mestrado em Economia Aplicada do primeiro autor.

Recebido em 02/09/2004 Aceito em 18/10/2004

${ }^{2}$ Mestre em Economia Aplicada, Departamento de Economia Rural, UFV. CEP 36570-000 Viçosa - MG. E-mail: willaraxa@hotmail.com

${ }^{3}$ Professora do Departamento de Economia Rural, UFV. CEP 36570-000 -Viçosa - MG. E-mail: vslirio@ufv.br

${ }^{4}$ Professor do Departamento de Economia Rural, UFV. CEP 36570-000 -Viçosa - MG. E-mail: mlsantos@ufv.br

${ }^{5}$ Professor do Departamento de Economia Rural, UFV. CEP 36570-000 -Viçosa - MG. E-mail: wvieira@ufv.br
} 


\section{Introdução}

A pecuária leiteira vem atravessando momentos de profundas mudanças desde o início dos anos 90, após a liberação dos preços do leite conjuntamente com a abertura comercial ao exterior e com a estabilização de preços na economia nacional. Para Gomes (2001), a partir de então, a cadeia do leite tem sido considerada a de maior transformação em todos seus segmentos.

Dentre as alterações verificadas, na última década, na bovinocultura de leite brasileira, destaca-se também o deslocamento da produção para regiões de cerrado, especificamente no estado de Goiás, e para as regiões do Triângulo Mineiro e Alto Paranaíba (Gomes, 2001), em Minas Gerais. No período de 1990 a 2000, enquanto Minas Gerais cresceu a uma taxa de 3,77\% a.a., as regiões do Triângulo Mineiro e Alto Paranaíba apresentaram taxas de 4,39\% a.a., maiores que as de regiões tradicionais, como Sul de Minas e Zona da Mata, que atingiram 3,09\% a.a. e $1,03 \%$ a.a., respectivamente ${ }^{6}$.

Em meio a todo esse deslocamento da produção e a outras tantas significativas modificações ainda em curso na pecuária de leite nacional, fatores tidos como de pouca importância, se comparados a técnicas de ganho de produção, sofreram, da mesma forma, substanciais alterações em seus conceitos, como é o caso da gerência rural.

De maneira geral, nos últimos dez anos, a administração de empresas rurais caracterizou-se por maior complexidade, dada a inevitável influência de fatores sociais, políticos, econômicos, tecnológicos e ambientais externos ao processo produtivo, anteriormente não considerados.

Assim, Queiroz (2001) ressaltou que o maior entrave ao desenvolvimento sustentável e competitivo da bovinocultura de leite, no Brasil, eram problemas gerenciais, recomendando-se, portanto, o aprimoramento dos

\footnotetext{
${ }^{6}$ Representam taxas geométricas de crescimento, significativas a $1 \%$, e calculadas pelo autor com base em dados da Embrapa Gado de Leite (http: // www.embrapa.br/ibge).
} 
processos administrativos dessas empresas antes da mudança de técnicas de produção, com vistas em ganhos de escala.

Como alguns dos principais pontos de estrangulamento da produção de leite nacional, Gottschall et al. (2002) identificaram também falhas no seu sistema administrativo, como a falta de planejamento pecuário, e no gerenciamento tanto do rebanho quanto da estrutura econômica dessas unidades de produção.

Para Chinelato (2004), o êxito na atividade leiteira relaciona-se diretamente com o conceito de gerência empregado e, somente por meio da absorção desses conhecimentos por parte dos produtores, tornar-se-ão factíveis a redução dos custos e o conseqüente aumento de rendimentos, mediante manipulação dos fatores de produção.

Dada a tradicional importância sócio-econômica da bovinocultura de leite para o Brasil, torna-se fundamental a elaboração de ferramentas de suporte à decisão relacionadas com a atividade, principalmente por dar sustentabilidade ao expressivo crescimento da produção verificado em Minas Gerais. Logo, neste trabalho desenvolveu-se um sistema computacional de apoio à decisão para propriedades produtoras de leite, nas quais são consideradas as características desse processo produtivo, e qual se aproxime do conceito atual de gerenciamento demandado por esse setor.

Especificamente, pretendeu-se:

a) Construir e validar um modelo matemático representativo do processo de produção de leite adotado pela empresa rural tomada como estudo de caso; e

b) Simular o comportamento do sistema produtivo dessa unidade de produção, sob diferentes cenários. 


\section{Metodologia}

\subsection{Referencial teórico}

Segundo Rodrigues (1996), o processo de tomada de decisão em sistemas de produção de leite, por mais elementar que seja, caracteriza-se pelo elevado nível de dificuldade, em razão da complexidade e da interrelação dos parâmetros envolvidos. Dessa forma, sua modelagem deve considerar o sistema produtivo como um todo, incluindo, assim, fatores tecnológicos, biológicos e econômicos.

Yamaguchi e Carneiro (1997) ressaltaram a importância de se desenvolver um mecanismo capaz de processar, conjuntamente, informações de natureza física, zootécnica, financeira e econômica, com a finalidade de subsidiar o processo decisório na atividade leiteira, caracterizada pela ocorrência de eventos sucessivos ao longo do tempo. Logo, evidencia-se a necessidade de estudos gerenciais que se aproximem da realidade e características inerentes a esses sistemas produtivos.

Métodos tradicionais de gerenciamento, apesar de úteis em algumas circunstâncias, serve como uma primeira aproximação, devido às suas simplificações e até mesmo à falta de informação, e limitam a compreensão da realidade complexa desses sistemas de produção e de sua relação com outros sistemas, tornando, portanto, questionável a veracidade de seus resultados.

Assim, utilizaram-se técnicas de abordagem sistêmica, como forma de melhorar o entendimento do funcionamento do sistema de produção de leite, por meio da explicitação das principais relações existentes entre variáveis presentes nessa atividade.

Essas técnicas fundamentam-se em modelos mentais, que representam, de maneira geral, o conjunto de crenças, teorias, conhecimentos e pressuposições de cada indivíduo com relação ao funcionamento desses sistemas. Para representar esses mapas mentais, lançou-se mão de diagra- 
mas de influência, os quais são constituídos por relações de causa e efeito entre as variáveis fundamentais do sistema, bem como pelas estruturas de feedback responsáveis por sua dinâmica.

Todavia, apesar de os diagramas de influência permitirem a identificação e organização dos componentes básicos de um sistema de maneira simples e clara, não consideram a precisão e o nível em que são afetados. Para isso, utilizaram-se técnicas de modelagem matemática presentes em modelos computacionais, construídos sobre os princípios de dinâmica de sistemas ${ }^{7}$.

\subsection{Modelo analítico}

Pidd (1996) definiu um modelo como a representação explícita de parte da realidade, com a finalidade de compreendê-la, gerenciá-la e controlála. Os modelos têm grande aceitação no planejamento, no projeto e no controle de sistemas complexos, pois, geralmente, a realização de experimentos com o mundo real é dispendiosa, quando não impossível.

No entanto, um modelo sempre será uma representação simplificada da realidade, com vistas em descrever um problema específico e são essas simplificações que os tornam usuais ao suporte à decisão (Turban e Aronson, 1998). A fidelidade da representação depende da capacidade dos modelos em incorporar tal complexidade, o que é conseguido, em grande parte, pelo uso de modelos dinâmicos.

Diferente de outras metodologias que focalizam uma condição futura ideal para o sistema, a dinâmica de sistemas revela como chegar ao presente, para, a partir daí, identificar os caminhos que conduzem a sua melhoria, por meio da observação de como o sistema causa as dificuldades que estão sendo encontradas (Forrester, 1994).

${ }^{7}$ Para maiores detalhes, ver Sterman (2000). 
Para Ford (1999), o processo de modelagem de dinâmica de sistemas compreende as seguintes etapas: familiarização com o sistema em estudo, delimitação do problema a ser tratado, elaboração dos diagramas de influência e identificação das realimentações, construção de diagramas de estoque e fluxo, estimação dos parâmetros do modelo, simulação e comparação dos resultados com a realidade, realização de análises de sensibilidade e avaliação do impacto de novas políticas ${ }^{8}$.

Embora desenvolvida em 1961, a metodologia de dinâmica de sistemas passou a ser mais utilizada apenas nos anos 90, após o desenvolvimento de softwares específicos, como Powersim, IThink e Vensim, que contribuíram para o aumento da aplicabilidade desse método. Esses aplicativos possuem recursos de representação visual que facilitam, significativamente, a modelagem e a simulação de sistemas ${ }^{9}$.

Assim, em virtude do expressivo crescimento da bovinocultura de leite na região do Triângulo Mineiro e Alto Paranaíba, verificado anteriormente, optou-se por selecionar, para estudo, uma unidade de produção pertencente a essa região, com vistas em dar sustentabilidade econômica a tal expansão da pecuária leiteira.

Logo, a Fazenda Girassol, situada no município de Perdizes - MG, foi escolhida por ser representativa, visto que possibilita realizar todas as etapas do processo produtivo de leite, além da disponibilidade de informações tanto quantitativas quanto qualitativas, de forma a não comprometer os resultados deste trabalho. Portanto, os dados necessários à construção do modelo dinâmico foram do tipo primário e obtidos diretamente de fichas do rebanho e registros contábeis dessa unidade de produção de leite.

\footnotetext{
${ }^{8}$ Entende-se por política as regras que determinam a decisão a ser tomada.

${ }^{9}$ Utilizou-se neste trabalho, para construção dos modelos dinâmicos, o software Powersim $2.5 \mathrm{c}$. Para maiores detalhes sobre a simbologia empregada nesse aplicativo, bem como das características das possíveis variáveis a serem usadas, consultar Powersim 2.5c (1996).
} 


\subsubsection{Abordagem sistêmica da bovinocultura de leite}

Tendo-se conhecimento de que o intervalo entre partos (IEP) ${ }^{10}$ representa uma medida de eficiência reprodutiva, procurou-se, então, verificar a relação entre esse índice e a dinâmica de estabelecimento do rebanho (Figura 1).

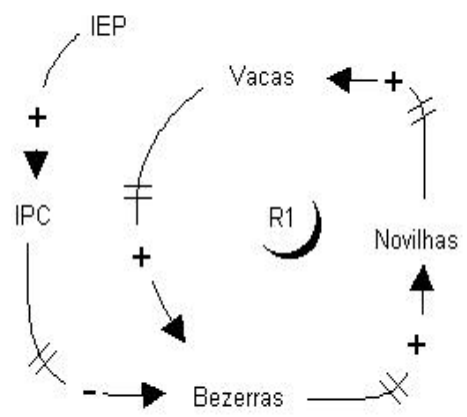

Fonte: Dados da pesquisa.

Figura 1 - Influência da eficiência reprodutiva na dinâmica de estabelecimento do rebanho leiteiro.

Nota-se que o IEP é responsável pela criação do loop de reforço (R1), que determina o crescimento do rebanho em maior ou menor intensidade conforme sua dimensão. Assim, quanto menor esse intervalo, menor o intervalo parto-concepção ${ }^{11}$ (IPC), maior o número de bezerras nascidas no sistema, maior o número de novilhas geradas no processo, maior o número de vacas do rebanho e, conseqüentemente, maior o número de

\footnotetext{
${ }^{10}$ Período de tempo existente entre duas parições sucessivas, normalmente medido em meses.

${ }^{11}$ Período de tempo existente entre a parição da vaca e sua nova concepção, geralmente medido em meses.
} 
bezerras presentes no sistema. Esse processo de realimentação, tudo o mais constante, continua indefinidamente com o passar do tempo ${ }^{12}$.

De outra forma, agindo no sentido de neutralizar o crescimento do rebanho, existem os loops de balanço B1 e B2. O primeiro se estabelece em razão da taxa de mortalidade de bezerras e acaba, por si só, gerando o loop de reforço R2, o qual efetivamente reduz o rebanho em conjunto com B2, que se dá em função da venda daquelas novilhas não necessárias à renovação do plantel.

Com o propósito de analisar os efeitos da eficiência reprodutiva na receita gerada pela venda de leite e de animais, construiu-se o diagrama de influência abaixo (Figura 2).

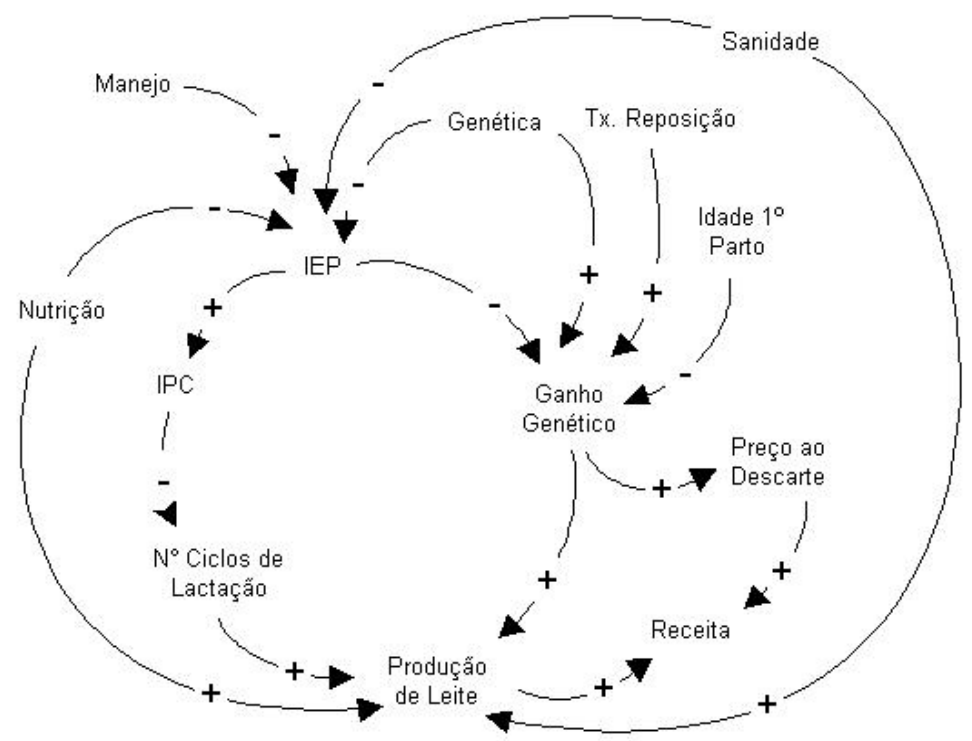

Fonte: Dados da pesquisa.

Figura 2 - Influência da eficiência reprodutiva na receita gerada pela atividade de bovinocultura de leite.

\footnotetext{
${ }^{12}$ Os traços nas setas do diagrama representam o fato de esses eventos não serem instantâneos, ou seja, são dependentes de determinado período de tempo para ocorrerem.
} 
Observa-se que quanto menor o IEP, maior o número de lactações de uma mesma vaca, em determinado período de tempo, o que resulta em maior produção de leite, determinando-se, portanto, a influência direta do fator reprodução na receita do leite. Percebe-se ainda que, no longo prazo, quanto menor o IEP, maior o ganho genético obtido em razão da maior rotatividade do rebanho, conjuntamente ao uso da técnica de inseminação artificial ${ }^{13}$, estabelecendo-se, assim, a rota indireta de elevação da produção e renda do leite via eficiência reprodutiva.

Como forma alternativa para incrementar o resultado financeiro do leite, tem-se o aumento da taxa de reposição que, mesmo em sistemas deficientes, do ponto de vista reprodutivo, pode resultar em maior ganho genético no futuro, pelos mesmos motivos descritos anteriormente. A idade no primeiro parto também se relaciona com tal benefício, uma vez que, quanto menor seu valor, menor o tempo necessário para a novilha expressar seu potencial de produção adquirido no melhoramento genético realizado.

Além da influência benéfica que a eficiência reprodutiva propicia à produção e renda do leite, esta ainda interfere na decisão relacionada com o preço de venda dos animais, já que este deixa de ser interessante, do ponto de vista produtivo do sistema, sendo, no entanto, atraente para o mercado. Em outras palavras, o animal encontra-se inadequado ao padrão produtivo do rebanho, mas adequado a outro processo produtivo menos exigente.

Captou-se, ainda, a relação direta existente entre os níveis de nutrição e sanidade adotados pela unidade de produção e o volume de leite produzido. Naturalmente, em rebanhos bem nutridos e saudáveis espera-se maior potencial de produção dos animais.

\footnotetext{
${ }^{13}$ Em rebanhos sob inseminação artificial espera-se que a filha seja sempre melhor do que a mãe, no que refere à produção de leite.
} 
Finalizou-se a análise sistêmica do processo produtivo da pecuária leiteira, explicitando-se as relações estabelecidas mediante a realização da renovação do rebanho, obtida por meio da adoção de determinada taxa de reposição (Figura 3).

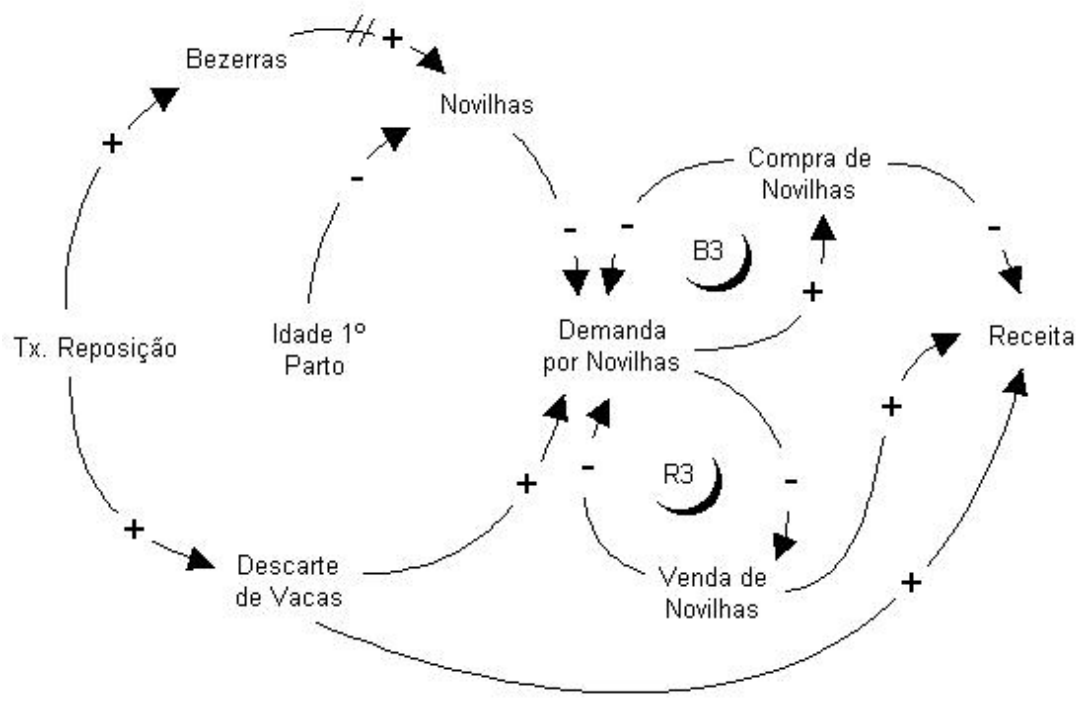

Fonte: Dados da pesquisa.

Figura 3 - Influência da taxa de reposição sobre a renovação do rebanho leiteiro.

Nota-se que, tudo o mais constante, quanto maior a taxa de reposição adotada, maior o descarte de vacas e, por conseguinte, maior a receita. Essa renovação elevada causa dois efeitos sobre a demanda de novilhas. O primeiro implica maior reposição, aumentando-se, assim, o número de bezerras nascidas e, futuramente, a quantidade de novilhas geradas, respeitada a idade desses animais, no primeiro parto. De outra forma, o segundo refere-se ao fato de que maior renovação do rebanho provoca elevação da necessidade de reposição, o que acaba afetando a demanda de novilhas. Por meio das relações explicitadas anteriormente, concluiu-se que a adoção de determinada taxa de renovação do plantel origina os loops R3 e B3. 
O loop R3, mediante decisões relacionadas com a venda de novilhas, determina o efeito desencadeado pela variação da demanda desses animais sobre a receita da atividade. De forma semelhante, o loop B3 também mede a influência na renda da exploração, ocasionada por alterações na referida demanda, considerando, no entanto, as decisões sobre a compra desses animais.

\subsubsection{Aplicação do modelo de simulação dinâmica}

Embora o sistema de apoio à decisão (SAD) construído possibilite, em curto espaço de tempo, a criação de diversos cenários, procedeu-se à simples interpretação das conseqüências de decisões simuladas, com relação somente ao funcionamento atual do sistema de produção analisado $^{14}$. Teve-se, portanto, apenas o propósito de facilitar o entendimento tanto das possibilidades de decisões, bem como da forma utilizada para se chegar aos resultados simulados (Interface) $)^{15}$.

\section{Resultados e discussão}

$\mathrm{Na}$ exposição do cenário referido no modelo de simulação dinâmica, optou-se por apresentar a seqüência de formulários que compõem a estrutura de interface do SAD concebido. Dessa forma, pode-se observar, primeiramente, a tela inicial do SIMULEITE - sistema desenvolvido com a finalidade de dar suporte ao processo decisório em propriedades rurais produtoras de leite (Figura 4) ${ }^{16}$.

\footnotetext{
${ }^{14}$ Para maiores detalhes sobre os modelos matemáticos desenvolvidos e o processo de validação utilizado, consultar Ávila (2004).

${ }^{15}$ Sintetizaram-se os resultados obtidos em valores numéricos, como forma de traduzir, em linguagem prática, as análises qualitativas características da metodologia de dinâmica de sistemas. Acredita-se que, dessa forma, não haja perdas significativas nas interpretações dos comportamentos estudados e, além disso, todos os indicadores selecionados representam estoques.

${ }^{16}$ Devido às limitações do software Powersim $2.5 \mathrm{c}$, no que diz respeito à elaboração de interfaces, optou-se pela construção desta, utilizando-se, como base, as ferramentas de Visual Basic, presentes no software Excel 7.0.
} 


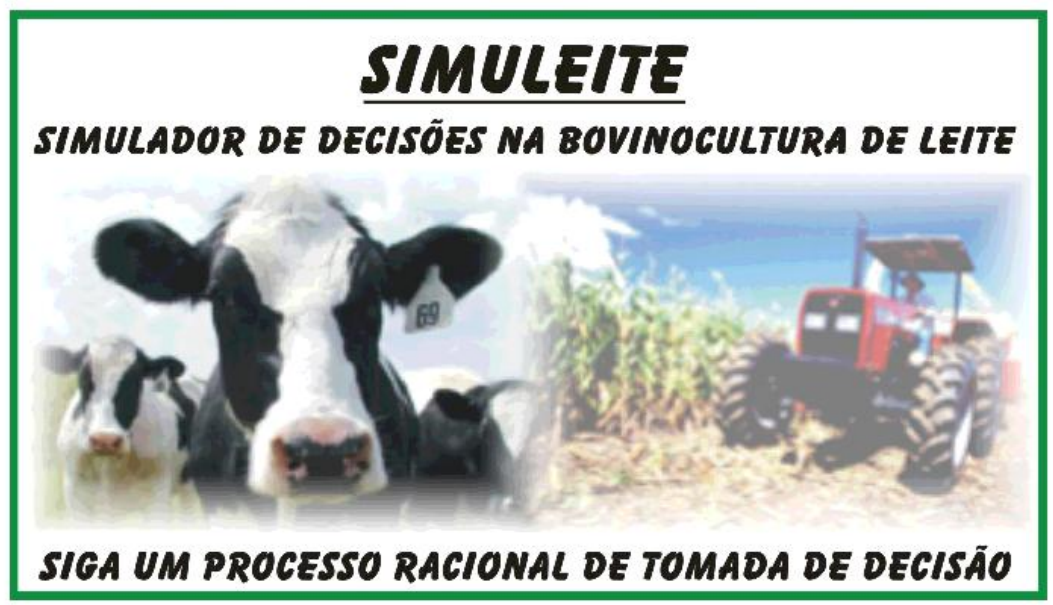

$\underline{\text { Sair }}$

Iniciar

Fonte: Dados da pesquisa.

Figura 4 - Formulário inicial do SIMULEITE.

Em seguida, determinam-se algumas das principais características que se pretende estabelecer em função das decisões a serem simuladas (Figura 5). 


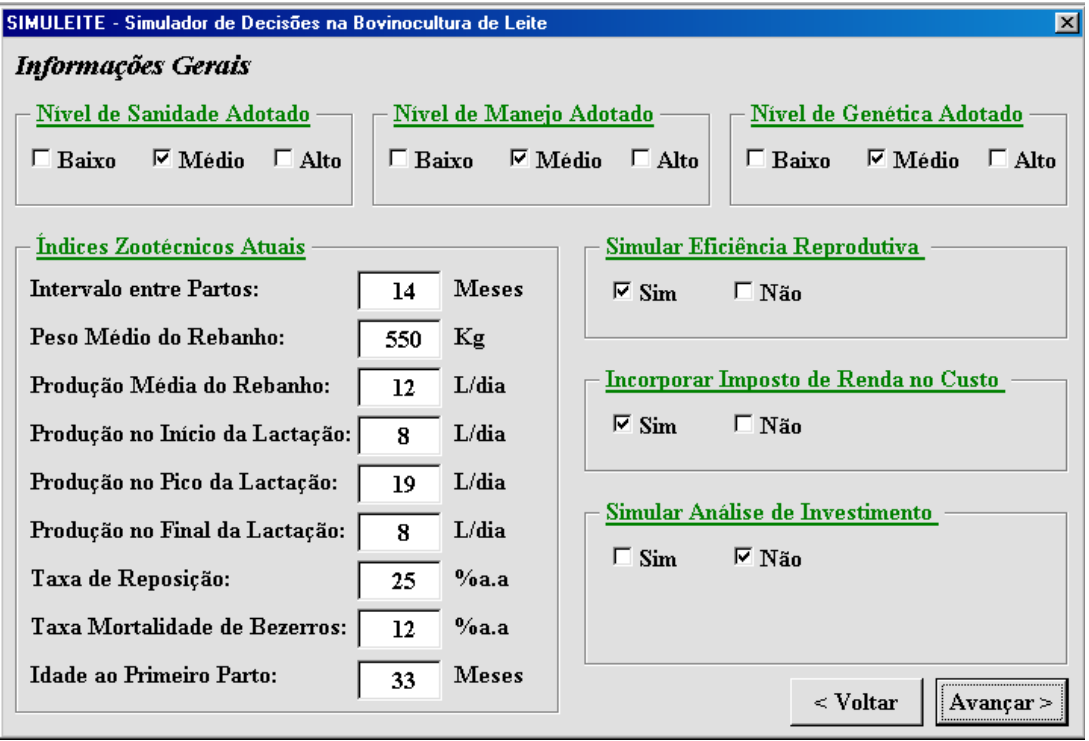

Fonte: Dados da pesquisa.

Figura 5 - Primeiro formulário de entrada de informações no SIMULEITE.

Posteriormente, pode-se optar pela simulação da eficiência reprodutiva. Se não for o caso, utiliza-se o mesmo intervalo entre partos, determinado no formulário ilustrado na Figura 5. Têm-se também a possibilidade de incorporar o imposto de renda no custo de produção e a oportunidade de avaliar algum investimento pretendido. Finalizado o preenchimento desse formulário, procede-se à informação da composição atual do rebanho, bem como dos preços dos animais pertencentes às respectivas categorias ${ }^{17}$ (Figura 6).

\footnotetext{
17 Ressalta-se que, embora se tenham discriminado as categorias de animais conforme a condução do processo produtivo da unidade de produção tomada como estudo de caso, pode-se, facilmente, adaptar o modelo a outras situações. Esse fato decorre da particularidade característica de cada sistema de apoio à decisão, com relação ao alcance do objetivo pretendido.
} 


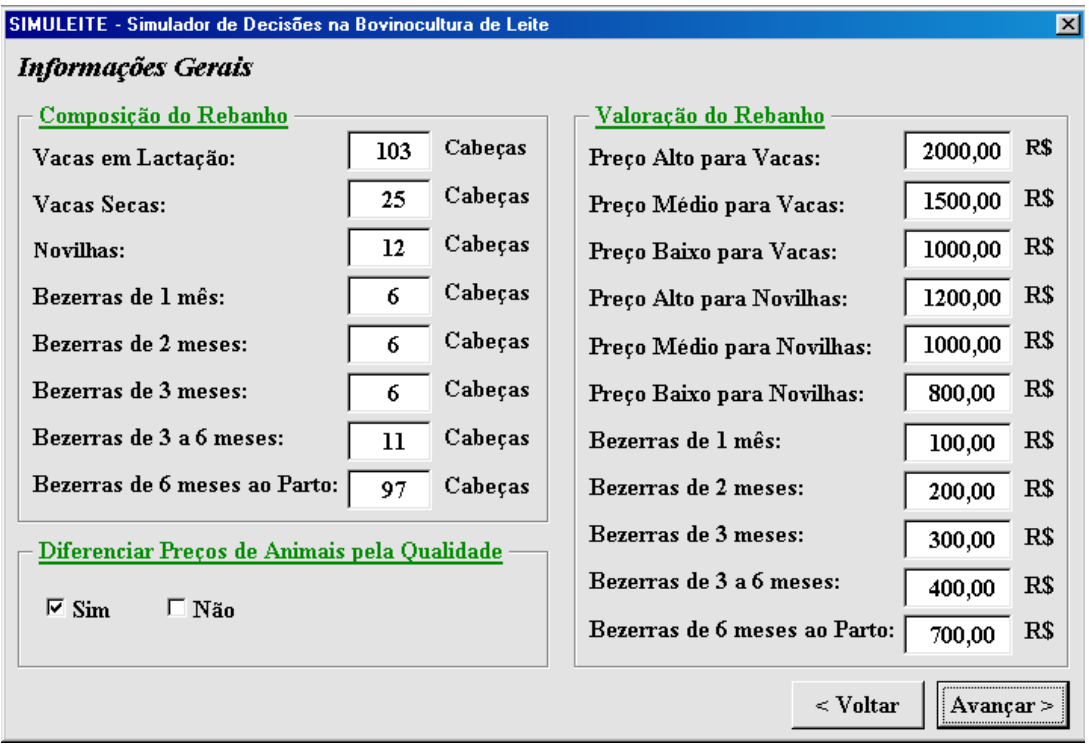

Fonte: Dados da pesquisa.

Figura 6 - Segundo formulário de entrada de informações no SIMULEITE.

Além disso, observa-se que, devido à variabilidade do padrão genético das vacas e novilhas de leite, optou-se por três preços para cada um desses grupos de animais. Percebe-se ainda que, em conformidade com as características de seu sistema de produção, o tomador de decisão pode simular os benéficos financeiros da realização do melhoramento genético do plantel. Caso decida pela não diferenciação da qualidade desses animais, considera-se a média dos preços praticados no mercado local.

Por outro lado, como um dos itens mais importantes na condução do sistema de produção de leite, tem-se a alimentação do rebanho. Dessa forma, explicitou-se o arraçoamento das diversas categorias de animais da unidade de produção (Figura 7). 


\begin{tabular}{|c|c|c|c|c|}
\hline \multicolumn{3}{|c|}{ SIMULEITE - Simulador de Decisōes na Bovinocultura de Leite } & \multicolumn{2}{|c|}{$x$} \\
\hline \multicolumn{5}{|l|}{ Informações Gerais } \\
\hline \multicolumn{2}{|l|}{ Alimentação do Rebanho } & \multirow{3}{*}{$\begin{array}{l}\text { Unidade } \\
\text { Kg MV/cab./dia }\end{array}$} & \multicolumn{2}{|c|}{ Precos Respectivos } \\
\hline Relação Leite/Concentrado: & 3 & & 0.51 & $\mathrm{R} \$ / \mathrm{Kg}$ \\
\hline Consumo de Silagem na Seca: & 30 & & 0.05 & $\mathrm{R} \$ \mathrm{Kg} \mathrm{MV}$ \\
\hline Consumo de Sal pelas Vacas: & 0.100 & $\mathrm{Kg} / \mathrm{cab} . / \mathrm{dia}$ & 1.02 & $\mathrm{R} \$ \mathbf{K g}$ \\
\hline Consumo de Sal pelas Novilhas: & 0.050 & $\mathrm{Kg} / \mathrm{cab} . / \mathrm{dia}$ & 0.61 & $\mathrm{R} \$ / \mathrm{Kg}$ \\
\hline Aleitamento Bezerras de 1 mês: & 4 & $\mathrm{~L} / \mathrm{cab} . / \mathrm{dia}$ & 0.60 & $\mathrm{R} \$ / \mathrm{L}$ \\
\hline Aleitamento Bezerras de 2 meses: & 3 & $\mathrm{~L} / \mathbf{c a b} . / \mathrm{dia}$ & 0.60 & $\mathrm{R} \$ / \mathrm{L}$ \\
\hline Aleitamento Bezerras de 3 meses: & 2 & $\mathrm{~L} / \mathrm{cab} . / \mathrm{dia}$ & 0.60 & $\mathbf{R} \$ / L$ \\
\hline Concentrado Bezerras de 1 mês: & 0.200 & $\mathrm{Kg} / \mathrm{cab} /$ dia & 0.50 & $\mathbf{R} \$ / \mathrm{Kg}$ \\
\hline Concentrado Bezerras de 2 meses: & 0.400 & $\mathrm{Kg} / \mathrm{cab} . / \mathrm{dia}$ & 0.50 & $\mathbf{R} \$ / \mathrm{Kg}$ \\
\hline Concentrado Bezerras de 3 meses: & 0.600 & $\mathrm{Kg} / \mathrm{cab} . / \mathrm{dia}$ & 0.50 & $\mathbf{R} \$ / \mathrm{Kg}$ \\
\hline Concentrado Bezerras de 3 a 6 meses: & 1.000 & $\mathrm{Kg} / \mathrm{cab} . / \mathrm{dia}$ & 0.50 & $\mathbf{R} \$ / \mathrm{Kg}$ \\
\hline & & & $<$ Voltar & Avançar > \\
\hline
\end{tabular}

Fonte: Dados da pesquisa.

Figura 7 - Terceiro formulário de entrada de informações no SIMULEITE.

Por fim, apresenta-se o quarto e último formulário de entrada de dados, necessário à realização das simulações dos comportamentos do processo produtivo, diante as diferentes decisões então tomadas (Figura 8). 


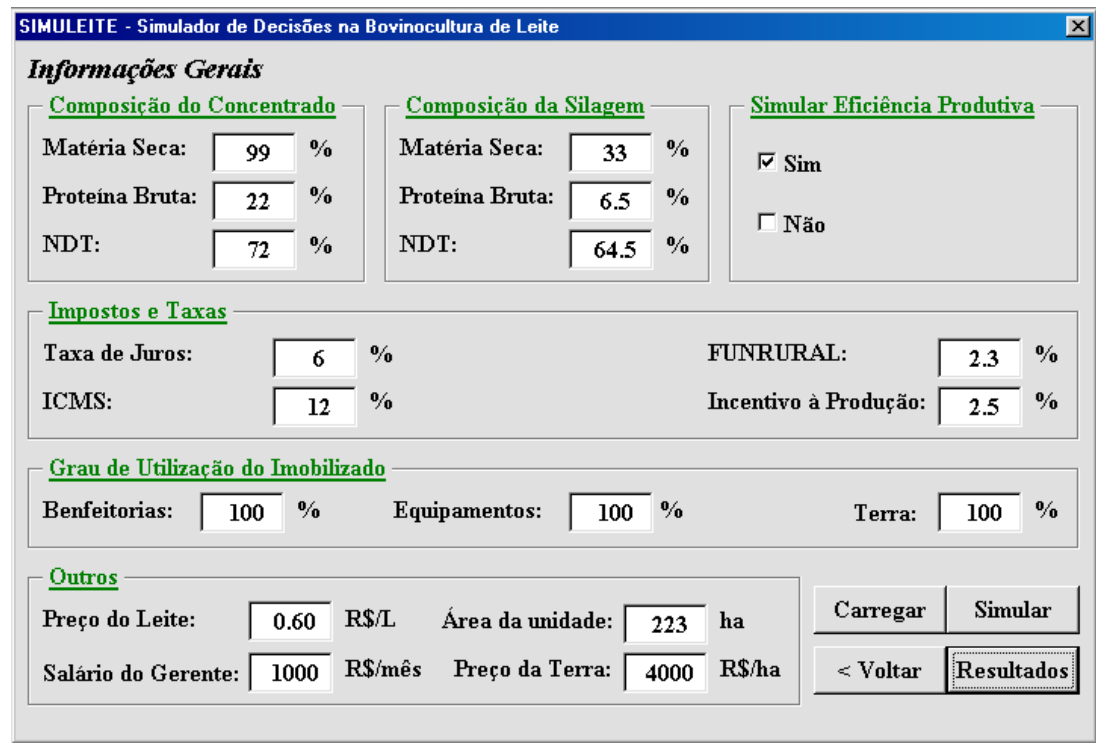

Fonte: Dados da pesquisa.

Figura 8 - Quarto formulário de entrada de informações no SIMULEITE.

Esse formulário trata de decisões de caráter geral. Inicia-se pela definição da composição nutricional do concentrado e da silagem fornecida às vacas em lactação, tornando-se, assim, possível o cálculo da demanda nutricional desses animais e a posterior classificação do nível de nutrição adotado, o qual define a eficiência produtiva.

A seguir, tem-se a definição dos valores dos impostos e das taxas considerados na simulação. Como forma de dar flexibilidade ao processo decisório, pode-se escolher o grau de utilização do capital imobilizado.

Finalmente, obtêm-se informações por meio da definição do preço do leite a ser considerado, do salário pretendido pelo administrador, da área destinada à atividade leiteira e do preço de venda da terra.

Definidos os parâmetros descritos em todos os formulários de entrada do SIMULEITE, procede-se à simulação e à posterior obtenção dos 
resultados. Primeiramente, apresentam-se os valores encontrados para os indicadores representativos do impacto das decisões sobre a estrutura física da empresa (Figura 9).

\begin{tabular}{|c|c|c|c|}
\hline \multicolumn{4}{|c|}{ SIMULEITE - Simulador de Decisōes na Bovinocultura de Leite } \\
\hline \multicolumn{4}{|l|}{ Resultados } \\
\hline \multicolumn{4}{|l|}{ Estrutura Física da Empresa } \\
\hline Número de Bezerros Nascidos: & 619,33 & Cab./Simulação & \\
\hline Número de Novilhas Produzidas: & 274,82 & Cab./Simulação & \\
\hline Número de Vacas do Rebanho: & 128,00 & Cab./Simulação & \\
\hline Número de Vacas Descartadas: & 160,00 & Cab./Simulação & \\
\hline Número de Novilhas Compradas: & 0,63 & Cab./Simulação & \\
\hline Número de Novilhas Vendidas: & 120,57 & Cab./Simulação & \\
\hline Produção Média de Leite: & $513.564,40$ & Litros/Ano & \\
\hline Consumo de Concentrado pelas Vacas: & 855,94 & Ton/Simulação & \\
\hline Consumo de Silagem pelas Vacas: & $3.014,40$ & Ton/Simulação & \\
\hline & & & Avançar > \\
\hline
\end{tabular}

Fonte: Dados da pesquisa.

Figura 9 - Primeiro formulário de resposta do SIMULEITE.

De acordo com a eficiência reprodutiva determinada pelo conjunto de decisões tomadas nesse cenário, obtiveram-se cerca de 619 nascimentos de bezerros ao longo da simulação (Com base nos dados fornecidos nos formulários anteriores). Nesse mesmo período, tornou-se possível, obviamente respeitada a idade ao primeiro parto de 33 meses, a subseqüente produção de, aproximadamente, 274 novilhas.

No que se refere à renovação do rebanho, observa-se que para um plantel de 128 vacas, como era de esperar, descartaram-se 160 animais, valor coerente com a taxa de reposição adotada, de $25 \%$ a.a. Nota-se, ainda, que o sistema foi capaz de produzir um excedente considerável de novilhas, uma vez que se tornou necessária a compra de somente cerca de 
um animal durante toda a simulação, enquanto se comercializaram, nesse mesmo espaço de tempo, aproximadamente 120 novilhas.

Com a finalidade de facilitar a interpretação por parte do produtor com relação ao volume de leite produzido, optou-se pela apresentação da média anual de leite produzido ao longo dos cinco anos simulados. Logo, obteve-se o valor de 513.564,40 L/ano para essa parametrização inicial.

Por fim, para se ter idéia da quantidade utilizada de concentrado e silagem no arraçoamento das vacas lactantes e, dessa forma, permitir o auxílio ao planejamento de sua produção, determinou-se o consumo desses insumos, encontrando, portanto, o montante de 855,94 ton/simulação, para concentrado, e 3014,40 ton/simulação, para consumo de silagem.

Com base nas características atuais da unidade de produção, visualizouse esse comportamento do sistema com relação a sua estrutura física. De outra forma, com o propósito de conhecer também o impacto dessas decisões na estrutura financeira da empresa, obtiveram-se os indicadores ilustrados na Figura 10.

\begin{tabular}{|c|c|c|c|}
\hline \multicolumn{4}{|l|}{ Resultados } \\
\hline \multicolumn{4}{|l|}{ Estrutura Financeira da Empresa } \\
\hline Custo Operacional Efetivo do Leite: & 0,42 & $\mathrm{R} \$ / \mathrm{L}$ & \\
\hline Custo Operacional Total do Leite: & 0,47 & $\mathbf{R} \$ \mathbf{L}$ & \\
\hline Custo Total do Leite: & 0,54 & $\mathbf{R} \$ / \mathbf{L}$ & \\
\hline Ponto de Equilíbrio do Leite: & $1.256,36$ & $\mathrm{~L} /$ dia & \\
\hline Margem Bruta da Atividade: & $133.452,90$ & R\$/Ano & \\
\hline Margem Liquida da Atividade: & $98.349,81$ & $\mathrm{R} \$ / A n o$ & \\
\hline Lucro da Atividade : & $53.267,91$ & R\$/Ano & \\
\hline Margem Bruta da Atividade por área: & 598,44 & $\mathrm{R} \$ / \mathrm{ha}$ & \\
\hline \multirow[t]{2}{*}{ Taxa de Remuneração do Capital: } & 6,55 & $\%$ a.a. & \\
\hline & & & $<$ Voltar \\
\hline
\end{tabular}

Fonte: Dados da pesquisa.

Figura 10 - Segundo formulário de resposta do SIMULEITE. 
Inicialmente, percebe-se que o setor de produção de leite mostrou-se rentável, do ponto de vista econômico, no curto e no longo prazo, uma vez que o valor simulado tanto para o custo operacional efetivo quanto para o operacional total do leite situou-se abaixo do preço de $0,60 \mathrm{R} \$ / \mathrm{L}$, definido para esse produto.

Para se ter idéia do volume de leite necessário para cobrir os custos totais de produção, determinou-se o ponto de equilíbrio, cujo valor encontrado, nessas condições atuais, foi de $1.256,36 \mathrm{~L} /$ dia.

Nota-se, adicionalmente, que tanto o setor de produção de leite quanto a atividade com um todo mostraram-se viáveis economicamente, no curto e no longo prazo, já que obtiveram médias anuais, para a margem bruta, margem líquida e lucro, de $\mathrm{R} \$ 133.452,90, \mathrm{R} \$ 98.349,81, \mathrm{R} \$ 53.267,91$, respectivamente. É provável que as diferenças significativas entre esses indicadores se deveram ao considerável patrimônio investido na pecuária leiteira praticada na unidade de produção em estudo.

Como conseqüência direta dessa dimensão da planta produtiva, observou-se o baixo valor encontrado para a margem bruta por área, se comparado ao valor de 854,05 R \$/há, encontrado para o milho, e ao de 996,63 $\mathrm{R} \$ /$ ha, determinado para a soja ${ }^{18}$. Verificou-se, além disso, que a taxa simulada para a remuneração do capital imobilizado foi de $6,55 \%$ a.a., valor ligeiramente superior à taxa mínima de juros paga pelas cadernetas de poupança.

Tais resultados indicaram que, guardadas as simplificações e limitações da ferramenta utilizada, apesar de a bovinocultura de leite ter apresentado retornos superiores aos custos envolvidos no processo produtivo, sua rentabilidade poderia aumentar com a elevação da capacidade de produção desse sistema.

\footnotetext{
${ }^{18}$ Analogamente ao realizado para a taxa de remuneração do capital quando de sua comparação com uma taxa alternativa de juros, recorreu-se ao levantamento das lucratividades por área de algumas das principais culturas produzidas em território brasileiro, baseando-se em dados do Agrianual 2004. Apesar de serem valores médios em nível nacional, acredita-se em sua validade a título de simples comparação.
} 


\section{Considerações finais}

Apesar de o sistema de suporte à decisão ter sido construído para uma única unidade de produção de leite, constatou-se a relevante contribuição de modelos mentais, explicitados na forma de diagramas de influência, na concepção de uma visão sistêmica da atividade leiteira, geralmente praticada em nível comercial no Brasil.

Além disso, os resultados obtidos das simulações dos modelos matemáticos, ao longo de toda sua etapa de validação, foram satisfatórios e coerentes com as análises sistêmicas previamente estabelecidas, o que possibilitou a utilização dessa ferramenta, desenvolvida neste trabalho no processo decisório envolvido, na atividade de pecuária leiteira.

Nesse sentido, conhecidas as particularidades características dos sistemas orientados à produção de leite, acredita-se que o sucesso desses empreendimentos esteja diretamente relacionado com a capacidade de gerar e processar informações, capazes de auxiliar, em potencial, esses empresários rurais em suas decisões.

Com efeito, pôde-se concluir que o uso da metodologia de dinâmica de sistemas foi capaz de aumentar o conhecimento da estrutura de funcionamento do sistema de produção de leite, estimulando, assim, a simulação de ações estratégias, com vistas em estabelecer um processo racional de tomada de decisão nessa exploração agropecuária.

No que se refere ao cenário estudado, observou-se que, embora nas condições atuais da empresa rural em análise, seus retornos financeiros sejam superiores aos custos incorridos durante o processo produtivo, sua rentabilidade poderia elevar-se mediante aumento da escala de produção. 


\section{Referências bibliográficas}

AGRIANUAL 2004. Anuário Estatístico da Agricultura Brasileira. São Paulo: FNP, 2004. 496p.

AVILA, W.R.B. Uso da Dinâmica de Sistemas como Ferramenta de Suporte à Decisão em Propriedades Rurais Produtoras de Leite: um estudo de caso. 2004. Dissertação de Mestrado. Programa de Pós-Graduação em Economia Aplicada, Universidade Federal de Viçosa, 2004.

CHINELATO, A. Vale a pena produzi leite em São Paulo? Balde Branco, São Paulo, ano 39, n. 472, p.24 - 28, fev. 2004.

FORD, A. Modeling the environment: an introduction to system dynamics modeling of environmental systems. Washington: Island Press, 1999. 401p.

FORRESTER, J.W. System dynamics, systems thinking, and soft OR. 1994. In: Road Map n. D-4405-4. Disponível em: <http:// sysdyn.mit.edu/road-maps/rm-toc.html>. Acesso em: 20 mar. 2003.

GOMES, S. T. Evolução recente e perspectivas da produção de leite no Brasil. In: O agronegócio do leite no Brasil. Juiz de Fora. Editora EMBRAPA. 2001, p. 49-61.

GOTTSCHALL, C. S.; FLORES, A. W.; RIES, L. R.; ANTUNES, L. M. Gestão e Manejo para a Bovinocultura Leiteira. 1.ed. Rio Grande do Sul: Editora Agropecuária Ltda, 2002. 182 p.

PIDD, M. Tools for thinking: modeling in management science. Rexdale: Wiley, 1996.350p.

POWERSIM 2.5. User's guide. Herndon: Powersim Press, 1996c. 
QUEIROZ, M.P. Gerenciamento vem antes de tecnologia. Balde Branco, São Paulo, ano 37, n. 438, p. 98, abr. 2001.

ROGRIGUES, L.H.A. Planejamento Auxiliado por Computador para Propriedades de Gado Leiteiro. In: CONGRESSO BRASILEIRO DE ENGENHARIA AGRÍCOLA, 25., 1996, Bauru. Anais... Bauru, 1996. CD-ROM.

STERMAN, J.D. Business dynamics-systems thinking and modeling for a complex word. Boston: Irwin McGraw-Hill, 2000. 982 p.

TURBAN, E.;ARONSON, J.E. Decision support systems and intelligent systems. New Jersey: Prentice-Hall, 1998. 890 p.

YAMAGUCHI, L. C. T., CARNEIRO, A. V. Aplicação de planilha eletrônica na análise técnica e econômica de unidades de produção de leite. In: CONGRESSO DA SOCIEDADE BRASILEIRA DE INFORMÁTICA APLICADA À AGROPECUÁRIA E À AGROINDÚSTRIA, 1, Belo Horizonte, 1997. Anais... Belo Horizonte, 1997. p. 95-99.

\footnotetext{
Abstract - The adequade management is the main factor of success in the milk production activity. In view of this, the objective of this paper was to develop a decision support tool based in system dynamics to be appled to this activity. To perform the simulations with the model they were used data from a representative milk production farm of the state of Minas Gerais, Brazil. The results obtained with simulations showed coherence with settled previously analysis. The system dynamics showed also to be very helpful to get a better understanding of milk production systems and to perform strategic planning.

Keywords: System dynamics, milk production, strategic planning.
} 